\title{
Level of comprehension in poetry of the grade five pupils of private schools in Surigao city
}

Lucero, Princes Arianne O. $\$

Surigao City Pilot School, Philippines (paolvidalucero18@gmail.com)

Alpahando, Quenched C.

Sukailang Elementary School, Philippines (quenalpahando20@gmail.com)

Estoque, Merlyn L.

Surigao State College of Technology, Philippines (merlynestoque20@ gmail.com)

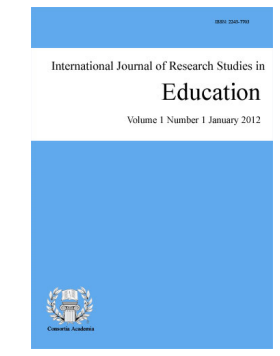

ISSN: 2243-7703 Online ISSN: 2243-7711

OPEN ACCESS

\section{Abstract}

Mindful of the need to articulate the level of comprehension in poetry of the learners, the study on level of comprehension in poetry of the Grade 5 pupils of the private schools in Surigao City was conducted. The study made use of the descriptive research using survey technique, with a researcher-made questionnaire containing 4 poems with 30 -item test, pilot tested to 30 pupils from Clementino V. Diez Memorial Central Elementary School (Cronbach Alpha $=.91$ ). A population of 133 Grade 5 pupils from St. Paul University Surigao, Surigao Education Center, and Surigao Sun Yat Sen Elementary School were taken as participants. T-test was used in testing differences which found no significant differences between the profile and the levels of comprehension in poetry, thus, being boys or girls does not affect the level of poetry comprehension. However, teacher should undergo trainings, seminars, and workshops on comprehension strategies in poetry focusing on the levels found to be low and school administrators are encouraged to support programs- such as the Saturday Remedial Classes on reading comprehension in poetry.

Keywords: applied; comprehension; interpretive; literal; poetry 


\section{Level of comprehension in poetry of the grade five pupils of private schools in Surigao city}

\section{Introduction}

Poetry is one of the many literary genres that are used by teachers in teaching vocabulary. It is the most widely used material in reading because of its accessibility and appropriateness for teaching reading. As has been experienced by teachers in the classroom, poetry captures the attention of the pupils as they learn about words and their meanings and as they are made to memorize and recite the poem before the class.

As an art form, poetry uses human language for its aesthetic qualities in addition to, or instead of, its notional and semantic content (poetry.org, 2005). The aesthetic qualities of poetry for children in particular, makes young readers get hooked into the material, thereby allowing them to delve into the contents and paving the way for comprehension and learning. Thus, in the context of reading, teachers need to determine the kinds of poetry that children will enjoy because such purpose will lead to the honing of the comprehension skills of the pupils.

Poetry comprehension involves the understanding of what the poem is about and looking into its elements such as rhyme, rhythm, sound devices, imagery and figurative language. It also means being able to get into the literal, interpretive, and applied levels of comprehension upon exposure on or after being exposed to the reading material. In the out-of-the-classroom context, avid readers of poetry read poems for instruction and entertainment purposes. The poem, its type, contents and author provide the motivation that leads to comprehension. Whether the material is popular or not, what matters to most readers is the flesh and the beauty that such poetry brings.

In the context of the classroom, teachers teach poetry primarily to develop, enhance and improve the learners' reading comprehension ability and to enrich their vocabulary acquisition skills. Alongside with the learning of the elements of a poem such as rhymes, sound devices, imagery and figurative language by the learners is ensuring their reading comprehension in view of the following levels- the literal, the interpretive, and the applied. Literal level involves understanding the specific information in the text; interpretive level involves integrating information and making inferences; while applied level involves using information from the text to construct knowledge (Centre for Canadian Language Benchmarks, 2015).

While Stanley (2004) believed that incorporating poetry into the classroom can help students develop vocabularies for speaking and writing, facilitate reading instruction, improve content area learning, and allow students to become more in tune with their thoughts and emotions, it is observed that learners find this learning area difficult. Accounted for is the fact that Filipinos are non-native English speakers; thus, comprehending literature such as poems in books, magazines and other reading materials is quite tough. Other reasons include factors related to the availability of reading materials in the home or in school which are supposed to be made available to the learners for purposes of enhancing their ability to read with comprehension. Whatever is the case, there is a need for teachers to constantly assess the learners as they acquire language competencies specifically in terms of their comprehension in reading, because in so doing, teachers would be able to plan, look for remedies, or make decisions to address the challenges brought about by the learners' inability to comprehend.

Thus, mindful of the need to articulate the level of comprehension in poetry of the learners, the researchers are prompted to conduct the present study specifically to the Grade 5 pupils, with the hope that interventions or remedies may be done if deemed necessary. 


\subsection{Conceptual framework}

The study was anchored on the concept stipulated in the Content Area Reading: Literacy and Learning Across the Curriculum (Vacca \& Vacca, 2008) which states that the three levels of comprehension- the literal, the interpretive, and the applied levels are reading conceptions from which teachers in school base their plan, design, and creating of reading activities in their classes that give pupils the opportunity to evaluate information on the reading selection. Such conceptualization was used in this study to assess the level of comprehension in poetry of the Grade 5 pupils of private schools in Surigao City.

As such, this research centered on assessing the level of comprehension of the Grade 5 pupils focusing on what is required by the curriculum. Following the concept upon which this study was anchored, the following variables are taken into consideration:

$>\quad$ Sex - This refers to the gender of the participants, either male or female.

$>$ Literal Level - This level involves the stimulation of thinking skills, which is associated with knowledge and comprehension abilities. It states the facts and details, rote learning and memorization. It is understanding the surface. The common questions used in this type of thinking are who, what, when, and where questions.

> Interpretive Level - This level involves reading between the lines and looking at what is implied by the material under study. In this level, it is implied or meant, rather than what is actually stated.

$>$ Applied Level - This level extends the concepts or ideas beyond the situation. Readers make use of higher-order thinking skills in text comprehension.

$>\quad$ Reading - Reading requires one to identify and understand strings of words in a fluid manner. It is a detailed process that includes comprehension, word recognition, engagement, and fluency (Sandhu, 2016).

$>\quad$ Poetry - It is an art form in which human language is used for its aesthetic qualities in addition to, its notional and semantic content (poetry.org, 2005).

$>\quad$ Reading Comprehension - This refers to the level of understanding of a text. It also means making meaning and engaging with the text intentionally and interactively. This includes literal, interpretive, and applied.

\subsection{Statement of the problem}

This study aimed at determining the level of comprehension in reading poetry of the Grade 5 pupils of private schools in Surigao City. It sought to answer the following questions:

What is the profile of the participants in terms of sex?

$>\quad$ What is the level of comprehension in reading poetry of the participants in terms of: a) literal; b) interpretive; and c) applied?

$>\quad$ Is there a significant difference in the level of comprehension in reading poetry of the participants when they are grouped according to sex?

$>$ Based on the results of the study, what intervention/s may be proposed?

Hypothesis - At .05 level of significance, it was hypothesized that there is no significant difference in the level of comprehension in reading poetry of the participants when they are grouped according to sex. 


\subsection{Significance of the study}

This study would provide updates and pieces of information on the existing fund of knowledge in Education specifically in the area of English and particularly on the concept of reading comprehension in poetry. Furthermore, the results of the study would be beneficial to the following groups of people and entities.

Pupils - This would enable them to become best writers and to create a solid foundation that can be built upon in their future endeavors.

English Teachers - The findings of the study would provide them ideas on the level of comprehension in poetry of their pupils. Moreover, these would help and guide them in thinking new strategies and approaches to better use poetry which could establish greater avenue for their pupils' learning.

General Education Teachers - Teachers who are handling non-English subjects would also find this information relevant because they would also require the learners to read in their classes since reading is also needed in other disciplines. Knowledge about the reading comprehension status of the learners will aid these teachers in designing reading activities for their classes.

School Administrators - The study would give them the information they need especially as far as reading comprehension of their pupils in schools is concerned. Through these pieces of information, they would be able to plan for remedial activities to address the problems related to such. Furthermore, they may make use of the data for purposes of curriculum planning, assessing, and reporting.

Parents - As the first teachers of their children, parents would be aware of the reading comprehension status of their children. Such knowledge would enable them to take actions to sustain or help augment the reading competencies and capabilities of the learners that are honed by the teachers in school.

Future Researchers - This study might guide them in their conduct of future similar researches.

\subsection{Scope and limitations of the study}

This study focused on determining the level of comprehension in reading poetry of the Grade 5 pupils of private schools in Surigao City. In determining the learners' comprehension, the literal, interpretive and applied levels of reading comprehension were looked into after the learners were made to read the poems. This study was conducted in the basic education department of St. Paul University Surigao, Surigao Sun Yat Sen Elementary School and Surigao Education Center.

\section{Review of related literature}

This section presents related articles, literature, studies and many other pieces of information culled from books, magazines and internet for the purpose of introducing ideas and concepts that provide linkage to the study at hand.

\subsection{Reading comprehension in poetry}

Comprehension is the reason for reading. If readers can read the words but do not understand or connect to what has been read, they are not actually reading. Good readers are both purposeful and active, and have the skills to absorb what they have read, analyze it, make sense of it, and consider it their own. Poetry comprehension involves understanding what the poem is about. The structure of the poem helps inform its meaning, but you want to identify what message the poet is expressing. Having identified the topic, look for the tone of the poem. Observe what emotions the poet's word choices convey. For example, do the words make the narrator sound angry, happy or in love? Use this information to identify the overall theme of the poem, meaning the poem's message. Themes relate to a larger idea such as love or death. The theme comes from what message

4 Consortia Academia Publishing (A partner of Network of Professional Researchers and Educators) 
Level of comprehension in poetry of the grade five pupils of private schools in Surigao city

the poet is communicating related to the larger issue. Use the tone to identify the poet's attitude toward the large idea; this will help you figure out the poem's meaning.

\subsection{The 3 Rs of poetry}

Poetry can produce good readers and can be very effective with struggling readers if it is used to teach particular skills and strategies. Applying the 3R's of poetry - rhyme, rhythm, and repetition, as stated by Stanley (2004), helps children "integrate textual clues for reading expressively while focusing on meaning." He strongly believes that poetry can help children to read. It feels that teachers who incorporate poetry into their daily literacy instruction will be amazed at the progress that the students make.

Poetry has a variety of rich descriptive vocabulary words that comes in many forms. In fact, Vecchione (2004) defined poetry simply as "a picture made of words." Poets can create beauty and a certain level of intensity in their works by choosing the words so carefully. Often, if the words are chosen carefully, this will force the reader to see things in a new way. Hearing the rich vocabulary in poetry makes children form images in their minds and bank this vocabulary for future speaking or writing. In preparation for an article on poetry, several poets were asked to define poetry (Kurkjian et al., 2004). It also appears that writing poetry with young students, as pointed out by Cicerchia (2015), encouraged them to use voice and to use a tremendous amount of creative language in their writing.

\subsection{Reasons for reading poetry}

Stanley (2004) believed that incorporating poetry into the classroom can help students develop vocabularies for speaking and writing, facilitate reading instruction, improve content area learning, and allow students to become clear and more in tune with their thoughts and emotions. Furthermore, he felt that poetry can help students "connect their experiences, ideas, emotions, and imagination in personal areas that might otherwise remain untouched." He further states that the use of multi-cultural poetry helps build a feeling of community with students and their peers. He also agrees that students can gain a more personal and meaningful experience from the more academic work if poetry is used as a brief anticipatory setup for content reading He trusts that poetry can build a bridge to content areas such as social studies, science, mathematics, history, and language.

Gregg and Skekeres (2007) share the belief that poetry can be helpful when teaching science and social studies concepts. Poetry can be integrated into the curriculum in so many ways and it will also allow students to experience success with poetry. The oral features of poetry acknowledge students' "unique need to incorporate the heard and spoken word with their vocabularies before attempting to read and write these words" (Hadaway et al., 2002). The literature consists of varied reasons why using poetry is beneficial to varied students. First, poetry stimulates oral-language development for all students due to its repetitive nature and quality. Stanley (2004) emphasized phonemic awareness and improves natural language acquisition. Oral language development helps children acquire language which is its important role. This is beneficial not only to emergent readers and writers in kindergarten and first grade but also to the ESL students in their classrooms as well.

Hadaway et al. (2001) felt that the rhyming and patterning of poetry can be an outstanding support for ELS students. The format that poetry is written in is not only helpful to ESL students but also to the struggling students as well. The short, concise form of many poems help to scaffold longer texts as well as practice with meaningful content (Hadaway et al., 2001). As cited by Keshavarz and Ashtarian (2008), there is a difference between males' and females' comprehension of the reading passages where females are outstandingly superior in reading skills. In addition, in terms of comprehension, females outperformed males in a written recall task.

\subsection{Teaching poetry}

Oczkus and Rasinski (2015) pointed that poetry helps students engage in the deep or close reading that is essential to proficient reading comprehension. In close reading, students are required to read a text more than 
once, but for different purposes. They also added that poetry is rich with interesting and unusual words, figurative language, imagery, simile, metaphor, and more.

Reading is a thoughtful process which embraces the idea of levels of comprehension. It has three levels namely literal, interpretive, and applied. Literal focuses only on what was said then what was meant by what was said (interpretive) and then extends (apply) the concepts beyond the situation (Bernardo, 2009). With these levels of comprehension, we can determine how far the child understands the texts or the content of the texts he reads. The ability of a child to comprehend texts through determining his level in comprehension can be easily assessed.

\subsection{The three levels of reading comprehension}

The three levels of reading comprehension or questioning techniques are presented from the least to the most sophisticated level, as follows: Level one is literal level where stimulation of thinking skills takes place and is associated with knowledge and comprehension abilities. It states the facts and details, rote learning and memorization. It is a surface of understanding. The common questions used in this type of thinking are who, what, when, and where questions. Level two is interpretive- where the reader is expected to read between the lines and to look at what is implied by the material under study. In this level, it is implied or meant, rather than what is actually stated, drawing inferences, tapping into prior knowledge and experience, attaching new learning to old information, making logical leaps and educated guesses. These categories are subjective, and the types of questions are thought-provoking questions like why, what if, and how. Level three is applied which takes what was said (literal) and then what was meant by what was said (interpretive) and then extend (apply) the concepts or ideas beyond the situation. Readers make use of higher-order thinking skills in text comprehension. At this level, readers synthesize information in the content material which will lead to constructing of additional input in reader-text transaction (Bernardo, 2009)

\subsection{Synthesis of the review}

The concepts obtained from the readings and literatures provided are related to this study. The idea of authors cited in this paper offered significant contribution to this piece of endeavor as the researchers looked into the level of comprehension in poetry. The literatures mentioned are similar to the present study because it talks of the levels of comprehension (Bernardo, 2009) and integration of poetry in the classroom (Oczkus \& Rasinski, 2015). However, the differences are the research locale and context. The present study focuses on the level of comprehension in reading poetry of the Grade 5 pupils of private schools in Surigao City.

\section{Materials and methods}

\subsection{Research design}

The study made use of the descriptive research design utilizing survey technique. This design was deemed appropriate because it aimed to determine the level of comprehension in reading poetry of the Grade 5 learners of the private schools in Surigao City.

\subsection{Participants}

The participants of this study were the Grade 5 pupils of St. Paul University Surigao, Surigao Education Center, and Surigao Sun Yat Sen Elementary School who were enrolled during the School Year 2016-2017. These schools are private schools in Surigao City Division. St. Paul University Surigao is a Roman Catholic private university run by the Sisters of Saint Paul of Chartres in Surigao City, Surigao del Norte, Philippines. Surigao Education Center is a private, non-sectarian, non-stock corporation. Surigao Sun Yat Sen Elementary School is a private elementary school that offers both English and Chinese curriculum. The researchers took

6 Consortia Academia Publishing (A partner of Network of Professional Researchers and Educators) 
$100 \%$ of the population of the Grade Five of the three schools. Among the grade levels in elementary, the researchers decided to take the Grade 5 pupils as the participants because while it is true that they already have gone through poetry in their lower years.

\subsection{Instrument}

The study made use of a researcher-made questionnaire to assess the level of reading comprehension in poetry of the Grade 5 pupils. Part I is on the profile of the participants in terms of sex, while Part II consisted of 4 two-stanza poems, with 30-item quiz derived from the said poems. These poems were taken from readworks.org. The questionnaire was subjected to content validation of experts and reliability tests. For the validity tests, the questionnaire was submitted to three experts in literature teaching for content validation, all of them are teaching English and Literature. For the reliability test, the Cronbach alpha $(\alpha)$ obtained was 0.91 which means that there is an excellent internal consistency.

Frequency count and percentage distribution - These tools were used to describe the profile of the participants.

Mean and Standard Deviation - This tool was used to obtain the average score and to determine the level of comprehension in poetry of the participants.

\subsection{Data gathering procedure}

The researcher submitted first the questionnaire to the adviser for thorough checking of the items. Right after the approval by the adviser, it was submitted to experts in literature teaching for content validation. After the validation, the researchers asked permission from the school principal of Clementino V. Diez Memorial Central Elementary School to conduct pilot testing in which the result was used in testing the reliability of the questionnaire. The said test was conducted in the Fast Learners Section of the school with 30 pupils. The result of the reliability was 0.91 , which is described as excellent in its internal consistency.

Prior to the administration of the questionnaire, letters of permit were sent to the School Heads/Principals of St. Paul University Surigao Grade School Department, Sun Yat Sen Elementary School and Surigao Education Center Grade School Department asking them permission to conduct the study. Upon approval by the school authorities, the researchers identified their participants through the teacher advisers and administered the poetry reading comprehension test to the Grade 5 pupils. After doing so, the data were collected, tallied, and submitted to the statistician for treatment. With the results at hand, the researchers then proceeded to data interpretation and analysis.

\subsection{Data analysis}

The data were subjected to the following statistical tools using SPSS Software. To assess the level of comprehension in poetry of the participants, the following parameters were used:

\section{Table 1}

Levels of interpretation

\begin{tabular}{cll}
\hline Parameter & \multicolumn{1}{c}{ Verbal Interpretation } & \multicolumn{1}{c}{ Qualitative Description } \\
\hline $7.50-10.00$ & Very High $(\mathrm{VH})$ & Comprehension is Advanced (CA) \\
$5.00-7.49$ & High (H) & Comprehension is Good (CG) \\
$2.50-4.99$ & Low (L) & Comprehension is Poor (CP) \\
$0.00-2.49$ & Very Low (VL) & Comprehension is Very Poor (CVP) \\
\hline
\end{tabular}

t-Test for Independent Samples - A t-test is used to test difference between two groups' averages. This tool was used in problem 3 to determine the significant difference between the level of comprehension (literal, 
Lucero, P. A. O., Alpahando, Q. C., \& Estoque, M. L.

interpretive, applied) in poetry in terms of sex.

Split-Half Reliability Test - This tool was used in getting the reliability of the test questionnaire.

\section{Results and discussion}

This chapter presents, analyzes, and interprets the data gathered in the study. The presentation follows the sequence of the problem posed in chapter 1.

\subsection{Profile of the participants}

Of the 133 participants, 66 or $49.62 \%$ of them are females and 67 or $50.38 \%$ are males. This means that most of the participants were males.

\subsection{Level of comprehension in poetry}

Table 2 displays the levels of reading comprehension in poetry of the participants in terms of literal, interpretive, and applied levels with their corresponding means, standard deviations and qualitative descriptions. Based on the statistical computations, literal level of comprehension (Mean=7.54, Standard Deviation=1.82) is verbally described as very high. This result tells that the pupils' comprehension is advanced in this level because they were able to identify facts and details and were able to answer the who, what, where and when questions about the poem. It should be noted that their comprehension in this level is very high, indicating that the pupils are advanced in their comprehension. According to Bernardo (2009), literal level of comprehension deals with understanding the surface only.

\section{Table 1}

Level of comprehension in poetry of the participants

\begin{tabular}{ccccc}
\hline Levels & Mean & $S D$ & Verbal Interpretation & Qualitative Description \\
\hline Literal & 7.54 & 1.82 & Very High & Comprehension is Advanced \\
Interpretive & 5.05 & 2.01 & High & Comprehension is Good \\
Applied & 4.32 & 1.77 & Low & Comprehension is Very Poor \\
\hline
\end{tabular}

Moreover, the interpretive level (Mean= 5.05, $S D=2.01$ ) is also verbally described as high, showing that the pupils' level of comprehension is good. Interpretive Level requires readers to read between the lines and think of the implied meanings and thoughts that the poem wishes to convey. Here, teachers pave the way to the pupils' comprehension by drawing inferences, tapping into their prior knowledge and experience, attaching new learning to old information, making logical leaps and educated guesses (Bernardo, 2009). This level is higher than the literal since it goes not only on the surface but into something deeper which is done through questions answerable by explanations introduced by how, why, what if, and other questions that lead students to do higher order thinking. Thus, the result tells that pupils are good at interpreting the poems because they were able to understand the implied meanings that the poems wanted to convey. However, it is also important to note that pupils' interpretive level in not very high, which tells that their comprehension is good, but not advanced.

On the other hand, applied level of comprehension (Mean $=4.32, \mathrm{SD}=1.77$ ) is verbally described as low, which means that in this level, the pupils' reading comprehension is poor. As pointed out by Bernardo (2009), applied level extend (apply) the concepts or ideas beyond the situation. Readers make use of higher-order thinking skills in text comprehension. At this level, readers synthesize information in the content material which will lead to constructing of additional input in reader-text transaction. It can be inferred then that the pupils found this level tough and difficult.

\subsection{Significant difference in the levels of comprehension in poetry}

For the significant difference in the levels of reading comprehension in poetry of the participants in terms of

8 Consortia Academia Publishing (A partner of Network of Professional Researchers and Educators) 
sex, $t$-test for independent sample was used. Findings revealed that there is no significant difference in all the levels of comprehension in poetry of the participants and their sex, (literal: $t(131)=1.1, p=.287$; interpretive: $t$ $(131)=2.3, p=.240$; applied $t(131)=1.2, p=.217)$, respectively. This means that there is no difference between male and female pupils in terms of their levels of reading comprehension in poetry. This connotes that male and female pupils acquire skills in reading comprehension the same way. It further implies that whether the pupils are male or female, their cognitive skills and abilities regarding reading comprehension in the three levels are alike.

This result does not match with the study of Keshavarz and Ashtarians (2008) which found out that there is a difference between the comprehensions of male and female participants in reading. According to such study, females are outstandingly superior in reading skills, and the proportion of men going to reading classes as a remedy, is higher than males.

\section{Proposed intervention on reading comprehension in poetry}

\section{Rationale}

The idea of creating the intervention for reading comprehension in poetry was conceived when the researchers conducted the study entitled, Level of Comprehension in Poetry of the Grade Five Pupils of the Private Schools in Surigao City, and found out that of the three levels (literal, interpretive and applied), interpretive and applied level were described as high/good and low/poor, respectively. Thus, this intervention activity is designed to promote comprehension strategies in poetry of the Grade 5 English teachers and the remediation for comprehension in poetry for the Grade 5 pupils, which would help them improve the interpretive and applied level of comprehension in poetry. The comprehension strategies on poetry seminar and workshop and the Saturday class for remediation for comprehension in poetry will be attended by the grade five pupils and English teachers which will be held in their designated schools.

\section{Proposed Seminar - Workshop on Reading Comprehension Strategies for the Grade Five English Teachers} of the Private Schools in Surigao City

\section{Program description}

The purpose of this program is to provide seminar-workshop/training on comprehension strategies in poetry, particularly on the interpretive and applied level of comprehension which will be conducted to the Grade 5 English teachers of private schools in Surigao City. In this intervention program, the teachers will be exposed to strategies that help improve pupils' understanding, integration of information (stated or implied) and application of the lessons learned about the poems. Interpretive level of comprehension includes drawing inferences, distinguishing between fact and opinion, and making logical leaps and educated guesses. Applied level of comprehension includes relating background knowledge to text content, evaluating author's reasoning, making predictions, and then applying the concepts or ideas beyond the situation.

\section{Remedial Saturday Classes on Comprehension in Poetry for the Grade Five Pupils of the Private Schools in Surigao City}

\section{Program Description}

The purpose of this program is to enhance or improve the comprehension level in poetry especially the interpretive and applied level of the Grade five pupils. They will attend Saturday classes which will be conducted by their English teachers. In this intervention program, the teachers who attended the seminar/workshop on comprehension strategies in poetry will be those who will conduct the said classes to improve pupils' comprehension in reading poetry particularly on the interpretive and applied level. The school 
Lucero, P. A. O., Alpahando, Q. C., \& Estoque, M. L.

shall allot honorarium for the teachers who will conduct the said classes and these honoraria will coming from the contributions of the pupils for Saturday classes. It will be a 3-hour class where activities on enhancing the interpretive and applied level of comprehension will be employed. These include drawing inferences, distinguishing between fact and opinion, and making logical leaps and educated guesses, relating background knowledge to text content, evaluating author's reasoning, making predictions, and then extending (applying) the concepts or ideas beyond the situation.

\section{Conclusions}

Based on the findings of the study, the following conclusions were given:

> The Grade 5 pupils can literally and interpretatively comprehend poetry, but have difficulty understanding the essence of the poems if applied in real life situations.

$>$ Being boys or girls does not affect the level of reading comprehension in poetry of the Grade 5 pupils.

$>$ Teachers use varied strategies to teach poetry and to develop the learners' level of comprehension.

$>$ Teachers use poetry to produce good readers and to help struggling readers.

$>$ Poetry helps learners in varied ways.

\subsection{Recommendations}

In the light of the foregoing findings and conclusions of this study, the following recommendations are established:

$>$ The teacher may undergo trainings, seminars, and workshops on comprehension strategies in poetry especially focusing on the interpretive and applied level of comprehension.

D Teachers may sustain the use of reading comprehension strategies but should design new methods to increase the interpretive level of comprehension from high to very high level of comprehension of the leaners.

$>$ The school administrators are encouraged to support programs- such as the Saturday Remedial Classes on reading comprehension in poetry to address the low level of comprehension skills in poetry of the pupils which is the applied level.

$>\quad$ Pupils may give ample time to read more poems to hone their comprehension skills in reading

$>$ Parents may always give time to monitor their child/children's performance in school, and encourage them to read poems or take time to read together with them.

$>$ Since the study focuses only to the levels of comprehension in poetry of the grade 5 pupils, it is hereby recommended to the future researchers to expand this study by considering the following:

- Factors affecting the level of comprehension in poetry of the pupils;

- Strategies on how to improve comprehension skills in poetry of the pupils; and

- Level of comprehension in poetry of the pupils in selected public schools in Surigao City.

10 Consortia Academia Publishing (A partner of Network of Professional Researchers and Educators) 
Acknowledgment - With sincere gratitude, the researchers wish to acknowledge the following whose ample and valuable help contributed much in the realization of this great endeavor. Foremost, to the most Divine source of life and energy for giving the researchers genuine, endless determination, fortitude and courage in pursuing this work amidst of inevitable test. To the researchers' parents, who provided them financial support, encouragement, and inspiration in making this work a success; Mrs. Louredil Longos for sharing in them her sincere assistance, guidance and expertise in fulfilling this task; Mr. Larry R. Dillo for guiding them throughout the finalization of the study, and for extending his professional skill in treating the data statistically; Dr. Maricar M. Saavedra for helping them in the formulation of the study; Dr. Merlyn L. Estoque, the researchers' adviser, for helping them in the editing process and for sharing her knowledge in illuminating the very essence of this work; All their classmates and friends who were always there to inspire them, to share their thoughts and laughter and to encourage them in pursuing this hard work.

\section{References}

Bernardo, A. (2009). Developmental reading 1. Rex Book Store.

Centre for Canadian Language Benchmarks. (2015). Level of comprehension and question types. Retrieved from https://realizeforum.ca/wp-content/uploads/2017/04/Handout-6.2-Levels-of-Comprehension-and-Questi on-types_2015.pd_.pdf

Cicerchia, M. (2015). Benefits of poetry for language learners. Retrieved from https://lingua.ly/blog/benefits-of-poetry/

Department of Education. (2016). K-12 curriculum guide in English. Retrieved from https://www.deped.gov.ph/wp-content/uploads/2019/01/English-CG.pdf

Gregg, M., \& Sekeres D. (2007). Poetry in third grade: Getting started. The Reading Teacher, 60(5), 466-475. https://doi.org/10.1598/RT.60.5.6

Hadaway, N., Vardell, S., \& Young, T. (2001). Scaffolding oral language development through poetry for students learning English. The Reading Teacher, 54(8), 796-806.

Hadaway, N., Vardell, S., \& Young, T. (2002). Choosing and sharing poetry with ESL students. Book Links, 51-56.

Keshavarz, M., \& Ashtarians, S. (2008). The relationship between Iranian EFL learners' gender and reading comprehension of three different types of text. Indonesian Journal of Applied Linguistics, 11(1), 97-113.

Kurkjian, C., Livingston, N., Young, T., \& Hopkins, L. B. (2004). Poetry: A feast for the senses. The Reading Teacher, 57(7), 694-696.

Oczkus, L., \& Rasinski, T. (2015). Five ideas that work: Positively poetry. International Literacy Association. Retrieved from https://www.literacyworldwide.org/blog/literacy-daily/2015/04/02/five-ideas-that-work-positively-poetr $\mathrm{y}$

Readworks (n.d.). Reading passages. Retrieved from https://www.readworks.org/rw/new-k-12-poems-and-question-sets\#!s0:374,29/q:/g:/t:/s:29/cid:/f:0/pt:A/ sr:false/features:/staff_picks:/sel:/

Sandhu, R. (2016). What is reading? Definition and process. Retrieved from http://study.com/academy/lesson/what-is-reading-definition-process.html

Stanley, N. (2004). Creating readers with poetry. Maupin House Publishing.

Vacca, R., \& Vacca, J. (2008). Content area reading: Literacy and learning across the curriculum (9th ed.) Pearson.

Vecchione, P. (2004). Language out of bounds: Ultimately, poetry defines the reason most educators are in the field. Leadership, 33(4), 23-25.

What is poetry? (2005). In poetry.org. http://poetry.org/whatis.htm 
Lucero, P. A. O., Alpahando, Q. C., \& Estoque, M. L.

12 Consortia Academia Publishing (A partner of Network of Professional Researchers and Educators) 